\title{
A New Variant of Android Educational Game as the Facility Introduction of Number for Early Childhood
}

\author{
D. A. Nawangnugraeni, Subiyanto \\ Department of Electrical Engineering \\ Universitas Negeri Semarang \\ Semarang, Indonesia
}

\begin{abstract}
This paper presents a new research, development and experiment evaluation of an android application game. The game is proposed as the educational facility to introduce number on early childhood. This educational game teaches a childhood to learn while playing that is learning numbers $0-9$ uses the media game on mobile smart phone with an operating system Android. The result of development was developed a game that consists of tutorial and game are implementing elements of the game. To evaluate the influence of educational game for learning outcomes carried on pre-kindergarten as many as $\mathbf{2 0}$ children and devided to the experimental group and the control group. The result of Gain score the experimental group is 0.77 (highest category) and the control group is $\mathbf{0 . 4 8}$ (medium category). Finally, the android educational game can use to be an educational facility that can improve learning outcomes number introduction of early childhood
\end{abstract}

Keywords - Game, educational game, Android, number introduction, early childhood

\section{INTRODUCTION}

Mathematics is a way of describing and representing the objects, space and the pattern governing community insight and ideas about the world with a systematic manner [1]. Basic mathematics skills that can be introduced in early childhood are introduction of number, counting, money value, problemsolving, logic, the concept of geometry measurements, statistical concept, sequence numbers and estimation [2]. The introduction of number taught in early childhood is pointed 110 , mentioning the order and pairing number using an object [3]. Implementation of learning in early childhood requires a media. The purpose of media is to facilitate communication and learning [4]. The children need physical media used to receive the message and encourage them to learn [5]. With physical media children will easily understand the material submitted. One media that can be used for learning facilities in early childhood is an educational game on a computer or tablet. The educational game can increase students' motivation and improve learning achievement [6]. Moreover, the educational computer games in elementary school nutrition course can improve the students' learning performance [7].

There are six elements characteristic of the game is rules, goals and objectives, outcomes and feedback, conflict/ competition/ challenge/ opposition, interaction, and representation or story [8]. An educational game should meet the element of the game. The educational game about introduction of numbers already developed before, but there still has some weakness, one of which is still can't complete the game elements [9].

Based on the description above, so an android educational game introduction of number on early childhood will be developed by applying the elements of the game. The development an android educational game can use to be an educational facility that can improve learning outcomes introduction of number in early childhood.

\section{OVERVIEW INTRODUCTION OF NUMBER AND ANDROID EDUCATIONAL GAME}

\section{A. Introduction of Number Concept}

Number including one of mathematical concept are used to calculate and measurement [2]. Learning number in early childhood need media because they will better understand the number concept using physical media. Using math apps can improve student learning in mathematics [10].

The introduction of mathematics usually starts at pre-school education students. Basic mathematics skills that can be introduced in early childhood are introduction of number, counting, value for money, problem-solving, logic, the concept of geometry measurements, statistical concept, sequence and the estimation [2]. The introduction of number taught in early childhood are counting/mention the sequence numbers of 1-10, counting with an indicated object from 1-5, indicates the sequence objects for numbers 1-5, connects/pair emblem numbers with objects from $1-5$, restate the new objects being viewed [3].

\section{B. Android Educational Game}

The game is a system in which players engage in an artificial conflict, defined by rules that produce measurable results [11]. There are six elements characteristic of the game is rules, goals and objectives, outcomes and feedback, conflict/competition/challenge/opposition, interaction, and representation or story [8]. The educational game is a game designed to teach people about a certain subject and to teach them a skill. With the game are taught us purpose, rules, 
adaptability, problem-solving, interaction all represented as a story [12]. The use of an educational game is a style of learning that the more relevant [13]. Many educational game have been developed for various subjects such us an educational game for a software engineering course [14], an online game was developed for conducting we based problem solving activities [15], a computer card game for learning computer literacy [16] and an educational game with innovative concept of generating three-dimensional interactive multimedia [17].

The educational game can increase students' motivation and improve learning achievement, such as an educational computer game for migratory bird identification is not only increasing motivation but also improve learning achievement for students [18]. Using game theory can increase the motivation of students [19]. Beside that, using digital game can increase the student to study with a scenario and provide an enjoyable, interactive and challenge [20]. A game based on ebook can improve the student learning achievement, selfefficacy and motivation of mathematics [21]. Particularly for kindergarten, board game, and other learning games that invite physical interaction contains an important role in developing and advancing motor skills [22]. It is very closely related to the essence form of the game that always show challenge problems need to find the solution by the user.

Android is an operating system a mobile device used to manage resources hardware for a smartphone or PC tablets [23]. Most android code released under open source license which means that anyone can use the android by downloading [24]. So, educational game android is a game that used to support learning on smartphone or PC tablet device with the android operating system. The research about comparison read on paper, a computer and a tablet show that use tablets can increase understanding reading [25].

\section{Basic Principles of Two-Dimensional Graphics}

Basic principles of two-dimensional graphics based on Klawoon in [26]. In addition to a geometric object, geometric transformations play a crucial role in computer graphics. Geometric transformations can be used to rotate, change or move objects step by step in animated scenes. The most important geometric transformations are scaling, rotation, shearing and translation.

A scaling leads to stretching or shrinking of objects in the direction of the $x$ - and $y$ - axis. A scaling $\mathrm{S}$ (Sx,Sy) maps the point $(\mathrm{x}, \mathrm{y})$ to the point $\left(\mathrm{x}^{\prime}, \mathrm{y}^{\prime}\right)$

$$
\left(\begin{array}{l}
x^{\prime} \\
y^{\prime}
\end{array}\right)=\left(\begin{array}{c}
s_{x} \cdot x \\
s_{y} \cdot y
\end{array}\right)=\left(\begin{array}{cc}
s_{x} & 0 \\
0 & s_{y}
\end{array}\right) \cdot\left(\begin{array}{l}
x \\
y
\end{array}\right)
$$

The rotations that are determined by a single parameter, the rotation angle. The rotation $\mathrm{R}(\theta)$ by the angle $\theta$ maps the point $(\mathrm{x}, \mathrm{y})$ to the point $\left(\mathrm{x}^{\prime}, \mathrm{y}^{\prime}\right)$ given by

$$
\left(\begin{array}{l}
x^{n} \\
y^{\theta}
\end{array}\right)=\left(\begin{array}{l}
x_{x} \cos (\theta)-y_{1} \sin (\theta) \\
x_{x} \sin (\theta)+y_{\cdot} \cos (\theta)
\end{array}\right)=\left(\begin{array}{cc}
\cos (\theta) & -\sin (\theta) \\
\sin (\theta) & \cos (\theta)
\end{array}\right) \cdot\left(\begin{array}{l}
x \\
y
\end{array}\right)
$$

Applying a shear transformation $\mathrm{Sh}(\mathrm{sx}, \mathrm{sy})$ to a point $(\mathrm{x}, \mathrm{y})$ yields the point $\left(\mathrm{x}^{\prime}, \mathrm{y}^{\prime}\right)$ with the new coordinates

$$
\left(\begin{array}{l}
x^{\prime} \\
y^{\prime}
\end{array}\right)=\left(\begin{array}{l}
x+s_{x} \cdot y \\
y+s_{y} \cdot x
\end{array}\right)=\left(\begin{array}{cc}
1 & s x \\
s y & 1
\end{array}\right) \cdot\left(\begin{array}{l}
x \\
y
\end{array}\right)
$$

A translation $T(d x, d y)$ causes a shift by the vector $\mathrm{d}=(\mathrm{dx}, \mathrm{dy})^{\mathrm{T}}$. This means the translation maps the point $(\mathrm{x}, \mathrm{y})$ to the point

$$
\left(\begin{array}{l}
x^{\prime} \\
y^{\prime}
\end{array}\right)=\left(\begin{array}{l}
x+d_{x} \\
y+d_{y}
\end{array}\right)=\left(\begin{array}{l}
x \\
y
\end{array}\right)+\left(\begin{array}{l}
d_{x} \\
d_{y}
\end{array}\right)
$$

\section{METHODOLOGY}

\section{A. Development Android Educational Game for Introduction of Number}

The first step in the development of Android educational game is to create an Activity Diagram design, interface design, animation and narrative or audio design, providing the hardware and sofware requirements. The activity diagram reference from Fowler in [27]. Fig. 1 is illustrating of a workflow and activity this Android educational game.

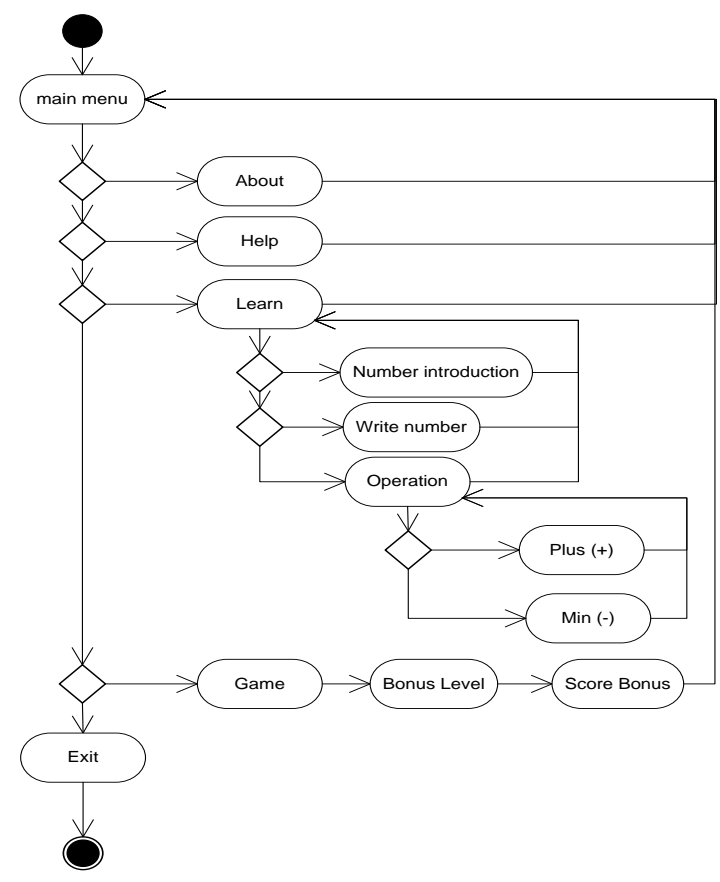

Fig. 1. Activity diagram of educational game Android

Fig. 2 showed the interface design of Learn Page on an educational game. The interface design description is in page there are four buttons, namely is Introduction of Number Button, Write Number Button, Operation Button and Back Button.

To move and change the position animation using transformasi geometric translation. The following calculation of translation in animation :

$$
\begin{array}{r}
\mathrm{x} 1=(\mathrm{X} 1, \mathrm{Y} 1) \quad \mathrm{x} 3=(\mathrm{X} 2, \mathrm{Y} 2) \\
\mathrm{x} 2=(\mathrm{X} 2, \mathrm{Y} 1) \quad \mathrm{x} 4=(\mathrm{X} 1, \mathrm{Y} 2) \\
\mathrm{x}^{\prime}=((\mathrm{X} 1+100),(\mathrm{Y} 1+0)) \\
\mathrm{x}^{\prime}=((\mathrm{X} 2+100),(\mathrm{Y} 1+0))
\end{array}
$$$$
\text { Translation }(100,0) \text { using (4) }
$$ 
$\mathrm{x} 3^{\prime}=((\mathrm{X} 2+100),(\mathrm{Y} 2+0)$

$\mathrm{x} 4^{\prime}=((\mathrm{X} 1+100),(\mathrm{Y} 2+0))$

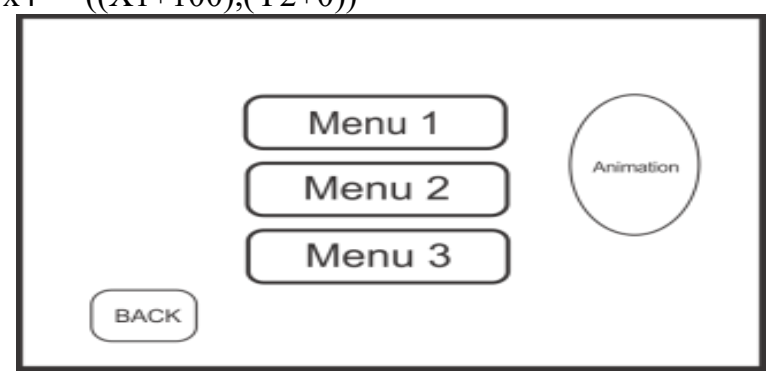

Fig. 2. Interface design of Learn Page

In addition to geometric transformations, in the game there is a back song audio and voice 'CLICK' when pressing the button.

The specification of software and hardware used for development educational game is Adobe Flash Professional CS6, Windows 7, CoreldrawX5 Portable, Windows Movie Maker, Format Factory, Operating system Kit Kat, Processor Intel(R) Atom(TM) CPU N570 1.67 GHz, RAM 2 GB, Harddisk 500 GB, Mouse, Keyboard, Monitor, Samsung Galaxy Tab 3 8.0. The Actionscript used to make the game is Actionscript 3.0, the script is:

- The script used to go to Learn Page

tombolbelajar.addEventListener (MouseEe nt.CLICK, kebelajar);

function

kebelajar (belajar:MouseEvent) : void\{ gotoAndStop ("pilih";

- The script used to play button in Write Number Page

var suaranol:angkanol=new angkanol(); tIs0.addEventListener (MouseEvent.CLIC, tulisol;

function tulis0(v:MouseEvent): void \{

tulisbsr.gotoAndStop (2);

tulisbsr.nol.gotoAndPlay (1); suaranol.play ();

The implementations of this educational game developed using Adobe Flash Professional CS6 application. The 2D objects creation on this game using the Rectangle Tool by adjusting the position $\mathrm{x}$ and $\mathrm{y}$. Fig. 3 is a tool that used to create $2 \mathrm{D}$ objects. Implementation of making an animation in the educational game using translation and scaling. To set the transformation of translation as shown in Fig. 4 and to set the transformation of scaling as shown in Fig. 5.

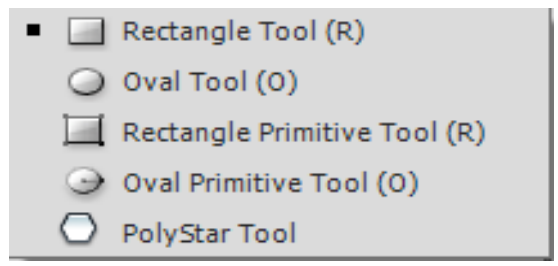

Fig. 3. Tool for $2 \mathrm{D}$ object

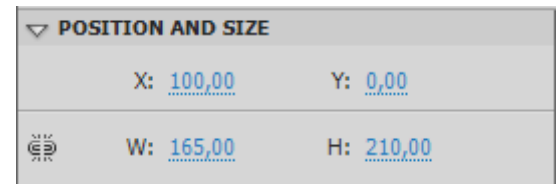

Fig. 4. Translation setting

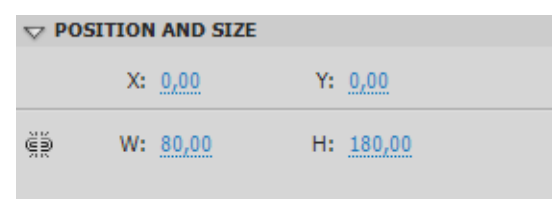

Fig. 5. Scaling setting

\section{B. Design Evaluation Experiment}

The experimental samples in this study are early childhood KBIT Mutiara Hati Patemon 4-5 years old. Students in grade amounted to 20 children, 10 students for the experimental group and 10 students for the control group. Each group will be taught by one teacher. The research instrument was used the sheets of pretest and posttest that consisting of 10 questions. An experiment lasted for 11 days.

In pre-test, the student must answer ten pieces question in a paper has been provided. After pre-test, the experimental group will be used an educational game and the control group used books in a learning process Implementation of the post-test same with pre-test that is answer 10 questions on sheet paper that has been provided. The results of pre-test and post-test on an experimental group and the control group will be analyzed by Gain Score. Procedures of experiment diagram can be seen from Fig. 6. An experiment diagram based on the Chu and Chang in [18].

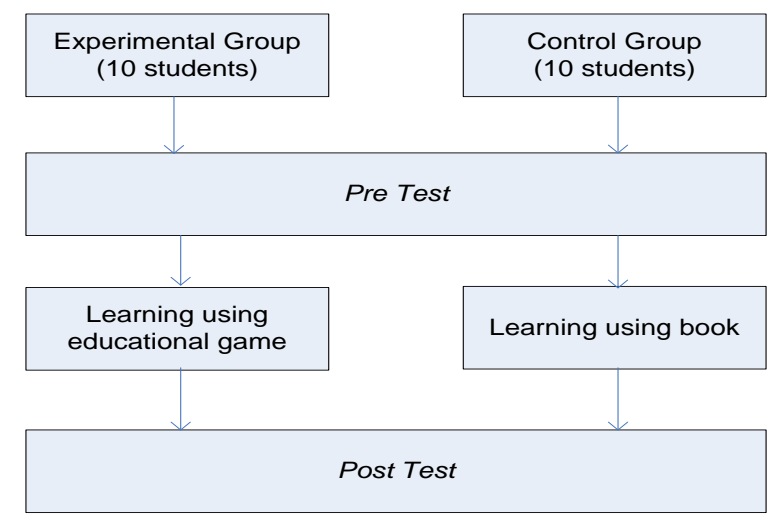

Fig. 6. Experiment diagram of educational game Android

\section{RESULT AND DSICUSSION}

\section{A. Result of Developing Android Educational Game}

An android educational game of number introduction is a game for early childhood, the game is made for smartphone device or tablet with an Android operating system. This educational game introduces number start of $0,1,2,3,4,5,6,7,8,9$ using pictures of objects, moreover the educational game also teaches children about the operation count. 
An educational game of number introduction developed named FUN MATH. This game consisting of Learning Menu, Game Menu, About Menu and Help Menu. The About menu and Help menu contains of information game and function of the game button. The Learning Menu contains about tutorials the introduction of number, write numbers and operation count. The Game Menu contains about the question of number and operation count. Introduction Page featuring about the number $0,1,2,3,4,5,6,7,8$ and 9. Fig. 7 showed the Introduction Page on the Learning Menu.

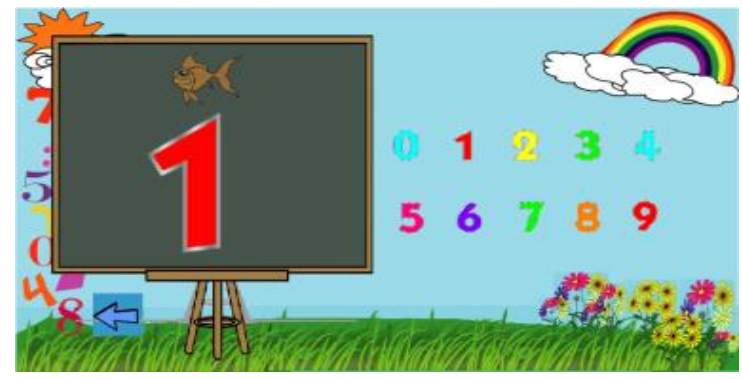

Fig. 7. Introduction Page

Write Page on the game contains tutorial about the manner writing number $0,1,2,3,4,5,6,7,8$ and 9 . This page there are 10 buttons number that will showed the manner of writing according to the selected number. Plus(+) Menu that contains three examples about the sum, Min(-) Menu contains three examples accompanied with the explanation about the reduction.

The Game Menu contains 20 questions consisting of 5 about counting pictures, 5 about sequence number, 5 about the addition and 5 about the reduction. The users can choose an answer by pressing a number button that provided. The correct answer will get score 5 and the wrong answer not to be reduced. At the end of play, children will be shown the score obtained. Fig. 8 showed the Game Page on the educational game.

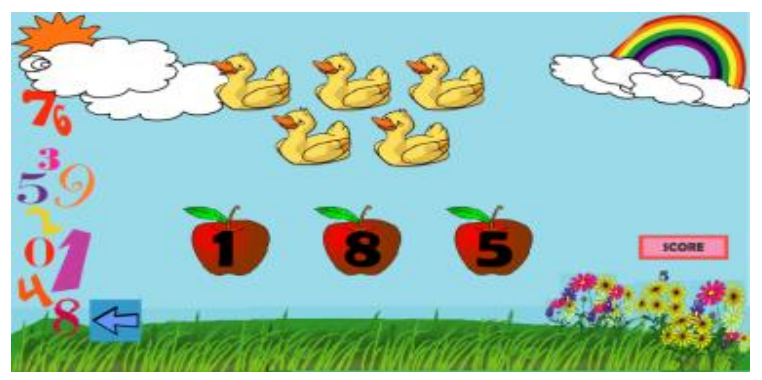

Fig. 8. Game Page

Objects animated of the game that using translation and scaling transformation there are on Learn Page and Introduction Page. Fig. 9 showed the Learn Page on the educational game.

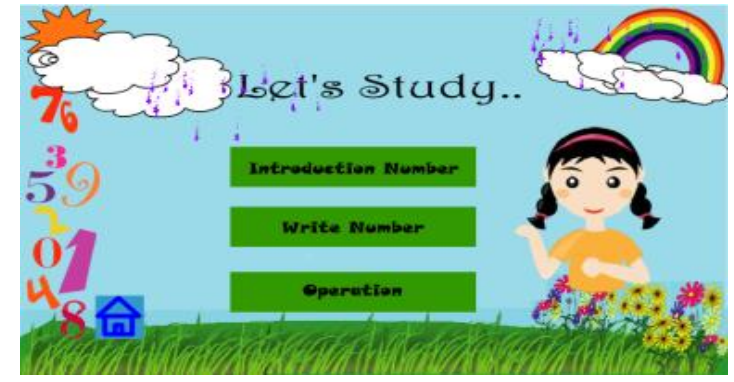

Fig. 9. Learn Page

\section{B. Result of Evaluation Experiment}

The results of a pre-post test on experimental group and control group can be seen in Table 1 while the average pretest and posttest can be seen in Fig. 10.

TABLE I. RESULT OF PRE TEST AND POST TEST EXPERIMENTAL GROUP AND CONTROL GROUP

\begin{tabular}{|c|c|c|c|c|c|}
\hline \multicolumn{2}{|c|}{ Experimnetal Group } & \multicolumn{3}{c|}{ Control Group } \\
\hline \multirow{2}{*}{ Sampel } & $\begin{array}{c}\text { Pre Test } \\
\text { score }\end{array}$ & $\begin{array}{c}\text { Post } \\
\text { Test } \\
\text { score }\end{array}$ & Sampel & $\begin{array}{c}\text { Pre Test } \\
\text { score }\end{array}$ & $\begin{array}{c}\text { Post } \\
\text { Test } \\
\text { score }\end{array}$ \\
\hline 1 & 0 & 60 & 1 & 10 & 20 \\
\hline 2 & 10 & 100 & 2 & 60 & 100 \\
\hline 3 & 60 & 100 & 3 & 20 & 20 \\
\hline 4 & 20 & 50 & 4 & 50 & 70 \\
\hline 5 & 60 & 80 & 5 & 60 & 100 \\
\hline 6 & 50 & 70 & 6 & 30 & 100 \\
\hline 7 & 40 & 100 & 7 & 10 & 20 \\
\hline 8 & 20 & 100 & 8 & 60 & 60 \\
\hline 9 & 60 & 100 & 9 & 40 & 90 \\
\hline 10 & 10 & 90 & 10 & 0 & 80 \\
\hline Sum & 330 & 850 & Sum & 340 & 660 \\
\hline Average & 33 & 85 & Average & 34 & 66 \\
\hline
\end{tabular}

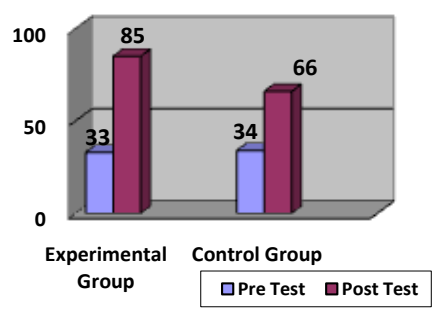

Fig. 10. Graph of pre test and post test average experimental group and control group

Based on the Fig. 10 explained that average post test score on experimental group higher than the control group. The change of average pretest and posttes in experiment using calculation the Gain Score [28]. 
Experimental group

$$
\begin{aligned}
(g) & =\frac{\left[\left(\%\left(\mathrm{~s}_{\mathrm{f}}\right)-\%\left(S_{i}\right)\right]\right.}{\left[(100)-\%\left(s_{i}\right)\right]} & (g) & =\frac{\left[\left(\%\left(\mathrm{~s}_{\mathrm{f}}\right)-\%\left(S_{i}\right)\right]\right.}{\left[(100)-\%\left(s_{i}\right)\right]} \\
(g) & =\frac{85-33}{[(100)-(33)]} & (g) & =\frac{66-34}{[(100)-(34)]} \\
& =0.77 & & =0.48
\end{aligned}
$$

Based on category, the Gain Score an experimental group is 0.77 that high category, and the control group is 0.48 that medium category.

\section{CONCLUSIONS}

In this paper, an android educational game introduction of number was developed. The game have been developed consists of tutorial and game are implementing elements of the game. The average and Gain Score of the experimental group is higher than the control group that is 0.77 (high category) and 0.48 (medium category). Based on research there is an increase in learning use of an educational game. Finally, the android educational game can use to be an educational facility that can improve learning outcomes introduction of number on early childhood.

\section{REFERENCE}

[1] Cross CT, Woods TA, Schweingruber H. Mathematics Learning in Early Childhood: Paths Toward Mathematics CoEC, editor.: The National Academies; 2009.

[2] Ismayani A. Fun Math With Children Jakarta: PT. Gramedia; 2010.

[3] Depdiknas. [Online]; 2003 [cited 2015 June 4].

[4] Heinich R, Smaldino SE, Russel JD, Molenda M. Instructional technology and media for learning New Jersey; 1996.

[5] Briggs LJ. Instructional design: principles and application New Jersey: Englewood Cliffs; 1997.

[6] Hwang GJ, Sung HY, Hung CM, Huang I, Tsai CC. Development of a personalized educational computer. Education Technology Research Development. 2012 Macrh; 60:623-638.

[7] Yien JM, Hung CM, Hwang GJ, Lin YC. A game-based learning approach to improving students'. The Turkish Online Journal of Educational Technology. 2011 April; 10(2).

[8] Prensky M. Fun, play and games: What makes games engaging New York: McGraw-Hill; 2001.

[9] GooglePlay. Learning number. [Online].; 2014 [cited 2015 Jan 5.

[10] Zhang M, Trussell RP, Gallegos B, Asam RR. Using math apps for improving students learning: an exploratorystudy in an inclusive fourth grade classroom. TechTrends. 2015 April; 59(2).

[11] Salen K, Zimmerman E. Rules of play: game design fundamentals: MIT Press; 2003.

[12] S GK. Educational games. [Online].; 2011 [cited 2015 June 2. Available from: HYPERLINK "http://teachinglearningresources.pbworks.com/w/page/351309 65/Educational\%20Games" http://teachinglearningresources.pbworks.com/w/page/3513096 5/Educational\%20Games

[13] Moreno-Ger P, Burgos D, Martines-Ortiz I, Sierra JL,
Fernandez-Manjon B. Educational game design for online education. Computers in Human Behavior. 2008 March.

[14] Connolly TM, Stansfield M, Hainey T. An application of games-based learning within software engineering. British Journal of Educational Technology. 2007; 38(3).

[15] Hwang GJ, Hu PW, Chen CC. An online game approach for improving students learning performance in web based problem solving citivities. Computer dan Education. 2012; 59.

[16]

[17] Beilikova M, Diveky M, Jurnecka P, Kajan R, Omelina L. Automatic generation of adaptive, educational and multimedia computer games. SIViP. 2008 October; 2.

[18] Chu HC, Chang SC. Developing an educational computer game for migratory bird identification based on a two-tier test approach. Education Technology Research Development. 2014 November; 62.

[19] Burguillo-Rial JC. Using game-theory and competition-based learning to stimulate student motivation and performance. Computer \& Education. 2012 September.

[20] Prensky M. The digital game-based learning New York: McGraw-Hill; 2001

[21] Carly S. The advantages of playing learning games with kids [Online].; 2014 [cited 2015 June 2. Available from: HYPERLINK "http://www.livestrong.com/article.214084-theavantages-of-learning-games-for-kids" http://www.livestrong.com/article.214084-the-avantages-oflearning-games-for-kids .

[22] Satyaputra A, Aritonang EM. Beginning android programming with ADT Bundle Jakarta: PT. Elex Komputindo; 2014.

[23] Lee WM. Beginning android application development Canada: Wiley Publishing; 2011

[24] Chen G, Cheng W, Chang TW, Zheng X, Huang R. A comparison of reading comprehension accros paper, computer sceens, and tablet: Does tablet familiarity matter? Journal Computer Education. 2014 August; 1.

[25] Klawonn F. Introduction to computer graphics: Computer science; 2012

[26] Martin F. UML distilled third edition a brief guide to standart object modeling language Boston: Pearson Education, Inc; 2003

[27] Hake RR. Analyzing change/ Gain scores USA: Indiana University; 1999.

[28] Hung CM, Huang I, Hwang GJ. Effect of digital game-based learning on students self-efficacy, motivation, anxiety and achievement in learning mathematics. Journal Computer Education. 2014 July; 1.

[29] Kordaki M, Papastergiou M, Psomos P. Student perceptions in the design of a computer card game for learning computer literacy. Education and Information Technology. 2014 September. 